\title{
ХАРАКТЕРИСТИКА ПОЛИСАХАРИДНЫХ КОМПЛЕКСОВ ВАСИЛЬКА ШЕРОХОВАТОГО (CENTAUREA SCABIOSA L.) И ВАСИЛЬКА ЛОЖНОПЯТНИСТОГО (CENTAUREA PSEUDOMACULOSA DOBROCZ.)
}

\author{
(C) М.С. Ларькина ${ }^{1 *}$, С.В. Кривощеков ${ }^{1,2}$, А.М. Гурьев ${ }^{1}$, Т.В. Кадырова ${ }^{1}$, Е.В. Ермилова ${ }^{1}$, \\ В.В. Коцерубская ${ }^{1}$, М.С. Юсубов ${ }^{1,2}$ \\ ${ }^{1}$ Сибирский государственный медицинский университет, Московский тракт, 2, \\ Томск, 634050 (Россия), e-mail: mmmaria@sibmail.com \\ ${ }^{2}$ Томский политехнический университет, пр. Ленина, 30, Томск, 634050 \\ (Россия)
}

Авторами статьи проведена характеристика полисахаридных комплексов василька шероховатого (Centaurea scabiosa L.) и василька ложнопятнистого (Centaurea pseudomaculosa Dobrocz.). Предложена методика последовательного выделения из надземных частей объектов исследования водорастворимых полисахаридов и пектиновых веществ. Установлено, что содержание водорастворимых полисахаридов в надземной части C. scabiosa в 2,8 раза больше $(2,7 \pm 0,3 \%, \mathrm{n}=3)$, чем в $C$. pseudomaculosa $(0,97 \pm 0,50 \%, \mathrm{n}=3)$, пектиновых веществ в надземной части $C$. scabiosa в 2 раза больше $(7,6 \pm 0,4 \%, \mathrm{n}=3)$, чем в $C$. pseudomaculosa $(3,9 \pm 0,3 \%, \mathrm{n}=3)$. Мономерными единицами полисахаридных комплексов C. scabiosa и C. pseudomaculosa являются остатки D-галактуроновой кислоты, L-рамнозы, D-ксилозы, D-маннозы, D-глюкозы и D-галактозы. Из водорастворимых полисахаридов C. scabiosa методом ионообменной хроматографии выделены три полисахаридные фракции (с молекулярными массами 667, 722 и 1027 кДа), мономерными единицами которых являются D-галактуроновая кислота, L-рамноза, D-галактоза, D-ксилоза и D-глюкоза.

Ключевые слова: водорастворимые полисахариды, пектиновые вещества, Centaurea scabiosa L., Centaurea pseudomaculosa Dobrocz., DEAE-целлюлоза, D-галактуроновая кислота.

\section{Введение}

Растения рода Centaurea сем. Asteraceae насчитывают около 800 видов, из них на территории Сибири и Дальнего Востока произрастает 16 видов василька. Род Centaurea издавна широко применяется в на-

Ларькина Мария Сергеевна - доцент кафедры фармацевтической химии, кандидат фармацевтических наук, e-mail: marialarkina@mail.ru, mmmaria@sibmail.com Кривощеков Сергей Владимирович - младший научный сотрудник, инженер, e-mail: ksv_tsu@mail.ru

Гурьев Артем Михайлович - руководитель Центра внедрения технологий, доктор фармацевтических наук, e-mail: titan-m@mail.ru

Кадырова Татьяна Владимировна - доцент кафедры фармацевтической химии, кандидат фармацевтических наук, e-mail: kadyrov2@sibmail.com

Ермилова Елена Васильевна - заведующая кафедрой фармацевтической химии, доктор фармацевтических наук, e-mail: nedel@mail.tomsknet.ru

Кочерубская Вероника Валерьевна - интерн

фармацевтического факультета,

e-mail: kocerubskaya@mail.ru

Юсубов Мехман Сулейман-огль - заведующий кафедрой химии СибГМУ, заведующий кафедрой технологии органических веществ и полимерных материалов, доктор химических наук, професcop, e-mail: yusubov@mail.ru родной и официнальной медицине [1-3]. На кафедре фармацевтической химии СибГМУ в течение нескольких лет проводились фитохимические и фармакологические исследования некоторых видов: Centaurea scabiosa L., Centaurea pseudomaculosa Dobrocz., Centaurea jacea L., Centaurea phrygia L. [4]. Установлено, что наиболее перспективными являются C. Scabiosa и C. pseudomaculosa, водные и водно-этанольные экстракты которых обладают выраженным противоописторхозным и антиоксидантным действием [5-7]. Кроме того, фармакологические исследования выявили наличие противосудорожных, антигипоксических и гепатопротекторных свойств у экстрактов C. scabiosa [8-10]. Изучение химического состава экстрактов данных видов показало, что основными группами биологически активных

\footnotetext{
* Автор, с которым следует вести переписку.
} 
веществ являются фенольные соединения (флавоноиды, гидроксикоричные кислоты, кумарины, дубильные вещества), сесквитерпеновые лактоны и полисахариды [11-14]. Следует отметить возрастающий интерес к изучению растительных полисахаридов в связи с их своеобразным строением, уникальными биологическими функциями и широким спектром физиологической активности (противовоспалительной, иммуномодулирующей и противоопухолевой и т.д.) [15-16]. Таким образом, изучение полисахаридных комплексов (ПСК) C. scabiosa и C. pseudomaculosa является актуальным.

Цель настоящей работы - изучение химического состава полисахаридных комплексов (ПСК) Centaurea scabiosa и Centaurea pseudomaculosa.

\section{Экспериментальная часть}

Растительный материал. Надземные части василька ложнопятнистого и василька шероховатого собраны в 2013 г. в окрестностях Томска и с. Заварзино Томской области соответственно. Надземные части заготавливали в фазе массового цветения и высушивали до воздушно-сухого состояния.

Общие аналитические методы. Идентификацию моносахаридов, входящих в состав ПСК, осуществляли после полного кислотного гидролиза 2 моль/л трифторуксусной кислотой (TFA) при нагревании в течение 5 ч при $100{ }^{\circ} \mathrm{C}$ в запаянной ампуле [17]. Избыток TFА удаляли многократным упариванием досуха со спиртом метиловым.

Моносахариды в гидролизате ПСК изучали методом ГЖХ-МС в виде соответствующих ТМСмоносахаридов. ТМС-моносахариды получали по следующей методике: к полученной в результате кислотного гидролиза смеси моносахаридов (после выпаривания досуха) добавляли 100 мкл безводного пиридина, смесь выдерживали в сушильном шкафу при $50^{\circ} \mathrm{C}$ в течение 20 мин. Далее добавляли 25 мкл $\mathrm{N}-$ триметилсилилимидазола (Sigma-Aldrich Chemie $\mathrm{GmbH}$, Германия), смесь выдерживали в сушильном шкафу при $70{ }^{\circ} \mathrm{C}$ в течение 40 мин. К полученной смеси ТМС-производных добавляли 1 мл гексана, интенсивно взбалтывали и оставляли до расслоения смеси. Далее верхний слой отбирали и анализировали ГЖХMC [18].

Хромато-масс-спектрометрию ТМС-эфиров проводили на газовом хроматографе «Agilent 7890A» (США) с масс-селективным детектором Agilent 5975C, капиллярной колонкой HP5MS (30 м × 250 мкм $\times$ 0,25 мкм), газ-носитель - гелий (скорость потока 1 мл/мин).

Содержание уроновых кислот (УК) в ПСК устанавливали карбазол-серным методом в пересчете на галактуроновую кислоту [18]; общее содержание белка - на основании реакции с биуретовым реактивом по методу Флореса [19], используя спектрофотометр Unico 2800 (США).

Молекулярно-массовое распределение в образцах определяли методом эксклюзионной ВЭЖХ по времени удерживания в соответствии с калибровочными значениями, определенными по стандартным образцам декстранов с помощью жидкостного хроматографа Ultimate 3000 «Dionex» (CША) с рефрактометрическим детектором, разделение проводилось на эксклюзионной колонке TSK-gel GMP XL 300x7,8 mm («Supelco», Япония), подвижная фаза - вода, 1,0 мл/мин.

${ }^{1}$ Н-ЯMР-спектры записывали на спектрометре Фурье AVANCE AV 300 фирмы Bruker (Германия), рабочая частота - 300 МГц, растворитель - $\mathrm{D}_{2} \mathrm{O}$. В качестве внутреннего стандарта использовали тетраметилсилан. Все значения химических сдвигов выражены в м.д. ( $\delta$-шкала) по отношению к ТМС.

Методика последовательного выделения водорастворимых полисахаридов (ВРПС) и пектиновых веществ (ПВ) из сырья. Навеску сырья (надземная часть василька шероховатого или василька ложнопятнистого) $(50,0$ г) заливали 1000 мл воды очищенной (соотношение сырья к воде $1: 20$ ) и нагревали на кипящей водяной бане в течение 2 ч при периодическом перемешивании. Затем процеживали извлечение, отжимали сырье, отделяли его от экстракта и фильтровали через бумажный фильтр. Заливали навеску сырья еще 500 мл воды очищенной и нагревали на водяной бане при идентичных условиях в течение 1 ч. Оставляли охлаждаться до комнатной температуры и фильтровали через многослойный тканевый фильтр. Фильтрат упаривали под вакуумом при температуре не более $50{ }^{\circ} \mathrm{C}$ до 100 мл. Полученный раствор медленно выливали в 300 мл 96\% спирта этилового и оставляли в прохладном месте для отстаивания осадка на 24 ч. Отстоявшийся раствор сливали, а осадок фильтровали через бумажный фильтр, промывая последовательно 96\% этанолом, этилацетатом и ацетоном. Затем осадок, не высушивая, переносили с фильтра в стеклянный стакан и растворяли в 100 мл воды очищенной при быстром перемешивании на магнитной мешалке в течение 3 ч при комнатной температуре. Полученный раствор центрифугировали (4000 об./мин, 30 мин) и упаривали супернатант до объема 40 мл. После этого раствор диализовали через целлофановую 
пленку OrDial D-Clean (Бельгия) с размером пор 5 кДа в течение 72 ч в 3000 мл воды очищенной при комнатной температуре, меняя воду через 12 ч. Затем раствор упаривали под вакуумом, замораживали и высушивали на лиофильной сушилке SP Scientific Advantage EL-85 (США).

Шрот сырья, оставшийся в колбе после извлечения ВРПС водой, использовали для извлечения ПВ $0,7 \%$ раствором оксалата аммония аналогично методике извлечения ВРПС.

Для количественного определения ПСК использовали гравиметрический метод [19].

Разделение ВРПС василька шероховатого на полисахаридные фракции проводили методом ионообменной колоночной хроматографии на DEAE-целлюлозе $\left(\mathrm{Cl}^{-}\right.$-форма, емкость сорбента $0,9-1,0$ мэкв/г, размер частиц 100-200 мкм) [20].

Навеску ВРПС василька шероховатого (0,300 г) растворяли в 0,01 моль/л растворе натрия хлорида, после центрифугировали в течение 5 мин 1500 об./мин. Отделяли раствор от осадка, далее раствор наносили на колонку $(24 \times 2,5$ см) с DEAE-целлюлозой («Whatman», Германия). Колонку последовательно промывали растворами хлорида натрия по 500 мл с возрастающей концентрацией $-0,01 ; 0,1 ; 0,2 ; 0,3 ; 0,4$ и 0,5 моль/л. Скорость элюента - 46 мл/ч. Отбирали фракции объемом по 25 мл. Выход полисахаридов из колонки контролировали качественной реакцией по методу Смита [21]. Полученные фракции концентрировали и очищали с помощью установки Vivaflow 200 (США) с использованием кассеты 5000 MWCO, замораживали и лиофильно высушивали.

\section{Обсуждение результатов}

Для выделения водорастворимых полисахаридов (ВРПС) и пектиновых веществ (ПВ) из надземных частей объектов предложена последовательная схема, позволяющая более комплексно использовать сырье. В качестве экстрагента для выделения ВРПС использовали воду очищенную с последующим осаждением в водном извлечении спиртом этиловым ПСК. Из шрота, оставшегося после выделения ВРПС, извлекали ПВ экстракцией $0,7 \%$ раствором оксалата аммония и последующим осаждением спиртом этиловым. При этом были подобраны следующие условия: двукратная экстракция на кипящей водяной бане, соотношение сырье - экстрагент $1: 20$ (первая экстракция) и $1: 10$ (вторая экстракция), время экстракции - 2 и 1 ч соответственно. Очистку от белков проводили переосаждением спиртом этиловым и центрифугированием осадка денатурированных белков. Для очистки от фенольных соединений, сапонинов, низкомолекулярных соединений использовали метод диализа через полупроницаемую мембрану. Изменение $\mathrm{pH}(\mathrm{pH}<7)$ используемых экстрагентов не привело к увеличению выходов ВРПС и ПВ, кроме того, возможен в таких условиях нежелательный гидролиз нативных полисахаридов. Полноту экстракции проверяли с помощью реакции с реактивом Фелинга после предварительного гидролиза ПС в извлечении $20 \%$ раствором серной кислоты. Экспериментально было определено, что полнота извлечения достигается при двукратной экстракции.

Установлено, что содержание ВРПС в надземной части C. scabiosa в 2,8 раза больше $(2,7 \pm 0,3 \%$, $\mathrm{n}=3)$, чем в C. pseudomaculosa $(0,97 \pm 0,50 \%, \mathrm{n}=3)$; ПВ в надземной части C. scabiosa в 2 раза больше $(7,6 \pm 0,4 \%, \mathrm{n}=3)$, чем в C. pseudomaculosa $(3,9 \pm 0,3 \%, \mathrm{n}=3)$ (табл. 1$)$.

Полученные полисахаридные комплексы (ПСК) - ВРПС и ПВ - были охарактеризованы по следующим показателям: качественному мономерному составу (содержание уроновых кислот (УК), содержание белка) и молекулярно-массовому распределению.

Мономерный состав всех выделенных ПСК изучали методом ГЖХ-МС после кислотного гидролиза. Водорастворимые полисахариды и пектиновые вещества изучаемых видов имеют схожий качественный мономерный состав, мономерными единицами которого по результатам анализа являются D-галактуроновая кислота, L-рамноза, D-ксилоза, D-манноза, D-глюкоза и D-галактоза.

Определение молекулярно-массового распределения выявило, что ВРПС C. scabiosa содержат два основных компонента с Мм - 1490 кДа $(62,5 \%)$ и 15 кДа $(33,6 \%)$, и два в незначительных количествах 1060 кДа $(1,7 \%)$ и 400 кДа $(1,7 \%)$ с общим содержанием УК $-63,7 \pm 3,9 \%(\mathrm{n}=5)$. ВРПС C. pseudomaculosa содержат также два основных компонента с Мм - 770 кДа (40,8\%) и 14 кДа (57,6\%), и один в минорном количестве - 440 кДа (1,6\%) с общим содержанием УК $-46,1 \pm 1,8 \%(\mathrm{n}=5)$. ПВ C. scabiosa содержат два основных компонента с Мм - 399 кДа $(55,8 \%)$ и 103 кДа $(37,9 \%)$, и один в минорном количестве - 32 кДа $(6,3 \%)$ с общим содержанием УК $-61,6 \pm 4,6 \%(\mathrm{n}=5)$. ПВ C. pseudomaculosa содержат один основной компонент с Мм 354 кДа $(84,4 \%)$ и два в минорных количествах - 92 кДа $(7,2 \%)$ и 15 кДа $(8,4 \%)$ с общим 
содержанием УК $-45,8 \pm 2,2 \%(n=5)$. Из полученных результатов установлено, что содержание уроновых кислот в ПСК василька шероховатого в 1,3 раза выше, чем в ПСК василька ложнопятнистого (табл. 1).

Содержание белка в ВРПС C. scabiosa - 6,8 $\pm 0,9 \%(\mathrm{n}=5)$, в ВРПС C. pseudomaculosa $-8,3 \pm 1,1 \%$, в ПВ C. scabiosa $-5,9 \pm 1,2 \%$, в ПВ C. pseudomaculosa $-7,8 \pm 1,2 \%$ (табл. 1).

Исходя из химико-фармакологических исследований василька шероховатого и учитывая более высокие выходы ВРПС и ПВ, чем в васильке ложнопятнистом, для более глубокого изучения химического строения ПСК следующим этапом проводили выделение полисахаридных фракций из ВРПС C. scabiosa и исследование их химической структуры. В результате ионообменной хроматографии ВРПС C. scabiosa на DEAE-целлюлозе водными растворами хлорида натрия возрастающей концентрации получены кислые полисахариды, которые элюировались из колонки 0,1 M (CS1), 0,1 M (CS2) и 0,2 M (CS3) растворами хлорида натрия.

Установлено, что все три фракции содержат белка менее $0,5 \%$. В состав фракций входит большое количество УК (CS1, CS2 и CS3: 28,2 $\pm 6,4 ; 40,6 \pm 5,2$ и 41,2 $\pm 5,4 \%$ соответственно, $\mathrm{n}=3$ ), что свидетельствует о кислой природе ПС.

Для определения гомогенности и чистоты полученные фракции проанализированы методом эксклюзионной ВЭЖХ. В результате хроматографического анализа установлено, что все исследуемые фракции имеют различные молекулярные массы: CS1 - 667 кДа, CS2 - 722 кДа, CS3 - 1027 кДа, основными мономерными звеньями которых являются D-галактоза, D-ксилоза, D-галактуроновая кислота, L-рамноза и D-глюкоза (табл. 2).

Для установления характера гликозидных связей в углеводных цепях полисахаридов фракций CS1, CS2 и CS3 применяли ${ }^{1} \mathrm{H}$-ЯМР-спектроскопию. Для идентификации полученных спектров использовали данные спектров стандартных образцов моно-, ди- и полисахаридов. Сигналы протонов в области 3,5-

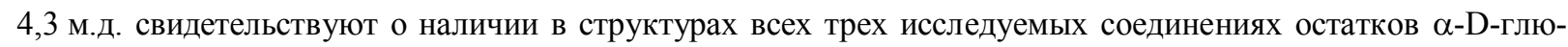
копиранозы, связанных $\alpha(1 \rightarrow 4)$-гликозидной связью. Интенсивный сигнал в области 3,7 м.д. соответствует протонам метоксигруппы (CH3-O), а сигнал в области 3,88 м.д. относится к сигналам протонов у атома углерода в 3-м положении у остатков $\alpha$-D-галактопиранозы и $\alpha$-D-глюкопиранозы. Кроме того, в спектрах соединений CS2 и CS3 наблюдаются сигналы 1,16 и 3,4 м.д., которые свидетельствуют о наличии в данных соединениях остатков $\alpha$-L-рамнопиранозы.

Таблица 1. Характеристика ПСК из надземных частей C. scabiosa и C. pseudomaculosa

\begin{tabular}{l|c|c|c}
\hline \multicolumn{1}{c|}{ Название фракций } & Выход*, \% & Содержание УК, \% & Содержание белка, \% \\
\hline ВРПС C. scabiosa & $2,7 \pm 0,3$ & $63,7 \pm 3,9$ & $6,8 \pm 0,9$ \\
ВРПС C. pseudomaculosa & $0,97 \pm 0,50$ & $46,1 \pm 1,8$ & $8,3 \pm 1,1$ \\
ПВ C. scabiosa & $7,6 \pm 0,4$ & $61,6 \pm 4,6$ & $5,9 \pm 1,2$ \\
ПВ C. pseudomaculosa & $3,9 \pm 0,3$ & $45,8 \pm 2,2$ & $7,8 \pm 1,2$ \\
\hline
\end{tabular}

* Выходы фракций оценивали в процентах от массы воздушно-сухого растительного сырья.

Таблица 2. Характеристика фракций из ВРПС C. scabiosa

\begin{tabular}{c|c|c|c|c|c}
\hline $\begin{array}{c}\text { Название } \\
\text { фракций }\end{array}$ & $\begin{array}{c}\text { Выход } \\
\%\end{array}$ & $\begin{array}{c}\text { Молекулярная } \\
\text { масса, кДа }\end{array}$ & $\begin{array}{c}\text { Содержание } \\
\text { УК, } \%\end{array}$ & $\begin{array}{c}\text { Содержание } \\
\text { белка, } \%\end{array}$ & Мономерный состав \\
\hline CS1 & 11,3 & 667 & $28,2 \pm 6,4$ & менее 0,5 & Gal A, Rha, Gal, Xyl, Glu \\
CS2 & 12,1 & 722 & $40,6 \pm 5,2$ & менее 0,5 & Gal A, Rha, Gal, Xyl, Glu \\
CS3 & 9,5 & 1027 & $41,2 \pm 5,4$ & менеe 0,5 & Gal A, Rha, Gal, Xyl, Glu \\
\hline
\end{tabular}

Примечание. * Выходы фракций оценивали в процентах от массы ВРПС, нанесенной на колонку. Gal A - D-галактуроновая кислота, Rha - L-рамноза, Gal - D-галактоза, Xyl - D-ксилоза, Glu - D-глюкоза.

\section{Выводы}

Предложена методика последовательного выделения из надземных частей объектов исследования водорастворимых полисахаридов и пектиновых веществ. Установлено, что надземные части василька шероховатого и василька ложнопятнистого содержат значительные количества водорастворимых полисахаридов и пектиновых веществ, при этом содержание их в васильке шероховатом в 2-3 раза выше, чем в васильке ложнопятнистом. Кроме того, содержание уроновых кислот в ПСК василька шероховатого в 1,3 раза выше, чем в ПСК василька ложнопятнистого. Мономерными единицами полисахаридных комплексов C. scabiosa и C. pseudomaculosa являются остатки D-галактуроновой кислоты, L-рамнозы, D-ксилозы, D-маннозы, D-глюкозы и D-галактозы. Из водорастворимых полисахаридов C. scabiosa, яв- 
ляющегося более перспективным объектом, методом ионообменной хроматографии выделены три полисахаридные фракции (с молекулярными массами 667, 722 и 1027 кДа), в структуре которых присутствуют остатки $\alpha$-D-галактопиранозы, $\alpha$-L-рамнопиранозы. $\alpha$-D-глюкопиранозы, связанные $\alpha(1 \rightarrow 4)$-гликозидной связью, D-галактуроновая кислота и D-ксилоза.

\section{Сиисок литературы}

1. Федорова А.А. Растительные ресурсы СССР: цветковые растения, их химический состав, использование; семейства Asteraceae. Л., 1987. 326 с.

2. Khammar A., Djeddi S. Pharmacological and Biological Properties of some Centaurea Species // European Journal of Scientific Research. 2012. Vol. 84, N3. Pp. 398-416.

3. Vele T., Dejan D., Vlatka V. Constituents of the roots of plants species Centaurea scabiosa // J. Serb. Chem. Soc. 1994. Vol. 59, N12. Pp. 979-981.

4. Кадырова Т.В., Ермилова Е.В., Краснов Е.А., Каминский И.П., Ларькина М.С., Дудко В.В. Химический состав перспективных растений, их антиоксидантная активность и фармакологическая активность // Новые достижения в химии и химической технологии растительного сырья : тезисы докладов Всеросс. науч. конф. Барнаул, 2007. С. 86.

5. Ларькина М.С., Сапрыкина Э.В., Кадырова Т.В., Ермилова Е.В., Пешкина Р.А. Антиоксидантная активность экстракта василька шероховатого при токсическом поражении печени крыс // Вопросы биологической, медицинской и фармацевтической химии. 2011. №8. С. 25-28.

6. Кадырова Т.В., Ларькина М.С., Ермилова Е.В., Краснов Е.А., Аврамчик О.А. Антиоксидантная активность экстрактов из надземной части Centaurea scabiosa L.(Asteraceae) // Растительные ресурсы. 2010. Вып. 1. С. $102-106$.

7. Каминский И.П., Краснов Е.А., Кадырова Т.В., Сазонов А.Э., Рахимова Б.Б., Ивасенко С.А., Адекенов С.М. Противоописторхозные свойства экстрактов из Centaurea scabiosa (Asteraceae) // Растительные ресурсы. 2010. №1. C. 106-112.

8. Ларькина М.С., Сапрыкина Э.В., Геренг Е.А., Кадырова Т.В., Ермилова Е.В., Пешкина Р.А. Гепатопротекторные свойства василька шероховатого // Вопросы биологической, медицинской и фармацевтической химии. 2011. №7. C. 28-32.

9. Ларькина М.С., Сапрыкина Э.В., Кадырова Т.В., Ермилова Е.В. Влияние экстракта василька шероховатого на содержание общих липидов и их отдельных компонентов у крыс с гепатитом // Фармация: современное состояние и перспективы : тезисы докладов Междунар. науч.-практ. конф. Алматы, 2010. С. 206-207.

10. Кадырова Т.В., Краснов Е.А., Корнякова А.В. Противосудорожные свойства экстрактов из Centaurea scabiosa (Asteraceae) // Растительные ресурсы. 2006. №4. С. 70-75.

11. Ларькина М.С., Кадырова Т.В., Ермилова Е.В. Фенольные соединения видов рода Centaurea мировой флоры (обзор) // Химия растительного сырья. 2011. №4. С. 7-14.

12. Ларькина М.С., Кадырова Т.В., Ермилова Е.В., Краснов Е.А. Количественное определение флавоноидов в надземной части василька шероховатого (Centaurea scabiosa L.) // Химико-фармацевтический журнал. 2009. №4. С. 14-17.

13. Ларькина М.С., Кадырова Т.В., Коваль В.В., Ермилова Е.В., Юсубов М.С. Флавоноиды надземной части василька шероховатого (Centaurea Scabiosa L.) // Химия растительного сырья. 2012. №4. С. 175-180.

14. Краснов Е.А., Каминский И.П., Кадырова Т.В. Антимикробная активность экстрактов из надземной части Centaurea scabiosa (Asteraceae) // Растительные ресурсы. 2012. №2. С. 262-266.

15. Оводов Ю.С. Полисахариды цветковых растений: структура и физиологическая активность // Биоорганическая химия. 1998. Т. 24, №7. С. 483-501.

16. Криштанова Н.А., Сафонова М.Ю., Болотова В.Ц. Перспективы использования растительных полисахаридов в качестве лечебных и лечебно-профилактических средств // Вестник ВГУ. 2005. №1. С. 212-221.

17. Корж А.П., Гурьев А.М., Белоусов М.В., Юсубов М.С., Белянин М.Л. Состав водорастворимых полисахаридов из цветков Calendula officinalis L. // Химико-фармацевтический журнал. 2012. №4. С. 23-25.

18. Galambos J.T. The reaction of carbazole with carbohydrates: I. Effect of borate and sulfamate on the carbazole color of sugars // Anal. Biochem. 1967. Vol. 19. Pp. 119-132.

19. Государственная фармакопея СССР: Вып. 2. Общие методы анализа. Лекарственное растительное сырье. 11-е изд. М., 1990. 337 с.

20. Neukom H., Deuel H., Heri W.J. Chromatographische Fraktionerung von Polysackariden an Cellulose-Anionenaustauschern // Helv. Chim. Acta. 1960. Vol. 43. Pp. 64-68.

21. Dubois M., Gilles K.A., Hamilton J.K., Rebers P.A., Smith F. Colorimetric method for determination of sugars and related substances // Analyt. Chem. 1956. Vol. 28. Pp. 350-356. 
Lar'kina M.S..$^{*}$, Krivoshchekov S.V. ${ }^{1,2}$, Gur'ev A.M. , Kadyrova T.V. ${ }^{l}$, Ermilova E.V. ${ }^{l}$, Kotserubskaia V.V. ${ }^{l}$, Iusubov M.S. ${ }^{1,2}$ CHARACTERISTICS OF THE POLYSACCHARIDE COMPLEXES ISOLATED FROM CENTAUREA SCABIOSA L. AND CENTAUREA A PSEUDOMACULOSA DOBROCZ.

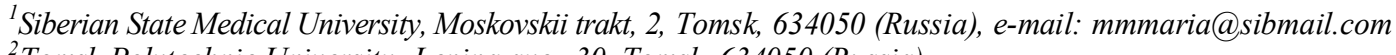

${ }^{2}$ Tomsk Polytechnic University, Lenina ave., 30, Tomsk, 634050 (Russia)

In the paper described comparative characteristic of polysaccharide complexes rough cornflower (Centaurea scabiosa L.) and lozhnopyatnistogo cornflower (Centaurea pseudomaculosa Dobrocz.). Was proposed the technique of sequential selection of water-soluble polysaccharides and pectins from the above-ground parts of the research objects. The content of water-soluble polysaccharides from the above-ground part of $C$. scabiosa is 2,8 times more $(2,7 \pm 0,3 \%, \mathrm{n}=3)$ than in $C$. pseudomaculosa $(0,97 \pm 0,50 \%, \mathrm{n}=3)$, pectins from the above-ground part of C. scabiosa is 2 times more $(7,6 \pm 0,4 \%, \mathrm{n}=3)$, than in C. pseudomaculosa $(3,9 \pm 0,3 \%, \mathrm{n}=3)$. The main monomer units of the polysaccharide complexes $C$. scabiosa and C. pseudomaculosa are D-galacturonic acid, L-rhamnose, D-xylose, D-mannose, D-galactose and D-glucose. From watersoluble polysaccharides of perspective C. scabiosa was isolated by ion exchange chromatography three fractions of polysaccharides (molecular weights of 667, 722 and $1027 \mathrm{kDa}$ ), which contain D-galacturonic acid, L-rhamnose, D-xylose, D-galactose and D-glucose.

Keywords: water-soluble polysaccharides, pectins, Centaurea scabiosa L., Centaureaa pseudomaculosa Dobrocz., DEAE-cellulose, D-galacturonic acid.

\section{References}

1. Fedorova A.A. Rastitel'nye resursy SSSR: tsvetkovye rasteniia, ikh khimicheskii sostav, ispol'zovanie; semeistva Asteraceae. [Plant resources of the USSR: flowering plants, their chemical composition, the use of; Asteraceae family]. Leningrad, 1987, 326 p. (in Russ.).

2. Khammar A., Djeddi S. European Journal of Scientific Research, 2012, vol. 84, no. 3, pp. 398-416.

3. Vele T., Dejan D., Vlatka V. J. Serb. Chem. Soc., 1994, vol. 59, no. 12, pp. 979-981.

4. Kadyrova T.V., Ermilova E.V., Krasnov E.A., Kaminskii I.P., Lar'kina M.S., Dudko V.V. Novye dostizheniia v khimii i khimicheskoi tekhnologii rastitel'nogo syr'ia: tezisy dokladov Vseross. nauch. konf. [New advances in chemistry and chemical technology of vegetable raw materials: abstracts of All-Russian Scientific Conference]. Barnaul, 2007, p. 86. (in Russ.).

5. Lar'kina M.S., Saprykina E.V., Kadyrova T.V., Ermilova E.V., Peshkina R.A. Voprosy biologicheskoi, meditsinskoi i farmatsevticheskoi khimii, 2011, no. 8, pp. 25-28. (in Russ.).

6. Kadyrova T.V., Lar'kina M.S., Ermilova E.V., Krasnov E.A., Avramchik O.A. Rastitel'nye resursy, 2010, issue 1, pp. 102-106. (in Russ.).

7. Kaminskii I.P., Krasnov E.A., Kadyrova T.V., Sazonov A.E., Rakhimova B.B., Ivasenko S.A., Adekenov S.M. Rastitel'nye resursy, 2010, no. 1, pp. 106-112. (in Russ.).

8. Lar'kina M.S., Saprykina E.V., Gereng E.A., Kadyrova T.V., Ermilova E.V., Peshkina R.A. Voprosy biologicheskoi, meditsinskoi i farmatsevticheskoi khimii, 2011, no. 7, pp. 28-32. (in Russ.).

9. Lar'kina M.S., Saprykina E.V., Kadyrova T.V., Ermilova E.V. Farmatsiia: sovremennoe sostoianie i perspektivy: tezisy dokladov Mezhdunar. nauch.-prakt. konf. [Pharmacy: current status and prospects: Abstracts of the International scientific-practical conference]. Almaty, 2010, pp. 206-207. (in Russ.).

10. Kadyrova T.V., Krasnov E.A., Korniakova A.V. Rastitel'nye resursy, 2006, no. 4, pp. 70-75. (in Russ.).

11. Lar'kina M.S., Kadyrova T.V., Ermilova E.V. Khimiia rastitel'nogo syr'ia, 2011, no. 4, pp. 7-14. (in Russ.).

12. Lar'kina M.S., Kadyrova T.V., Ermilova E.V., Krasnov E.A. Khimiko-farmatsevticheskii zhurnal, 2009, no. 4, pp. 14-17. (in Russ.).

13. Lar'kina M.S., Kadyrova T.V., Koval' V.V., Ermilova E.V., Iusubov M.S. Khimiia rastitel'nogo syr'ia, 2012, no. 4, pp. 175-180. (in Russ.).

14. Krasnov E.A., Kaminskii I.P., Kadyrova T.V. Rastitel'nye resursy, 2012, no. 2, pp. 262-266. (in Russ.).

15. Ovodov Iu.S. Bioorganicheskaia khimiia, 1998, vol. 24, no. 7, pp. 483-501. (in Russ.).

16. Krishtanova N.A., Safonova M.Iu., Bolotova V.Ts. Vestnik VGU, 2005, no. 1, pp. 212-221. (in Russ.).

17. Korzh A.P., Gur'ev A.M., Belousov M.V., Iusubov M.S., Belianin M.L. Khimiko-farmatsevticheskii zhurnal, 2012 , no. 4, pp. 23-25. (in Russ.).

18. Galambos J.T. Anal. Biochem., 1967, vol. 19, pp. 119-132.

19. Gosudarstvennaia farmakopeia SSSR: Vyp. 2. Obshchie metody analiza. Lekarstvennoe rastitel'noe syr'e. [The State Pharmacopoeia of the USSR: Vol. 2. General methods of analysis. Medicinal plant material]. 11 ed., Moscow, 1990, 337 p. (in Russ.).

20. Neukom H., Deuel H., Heri W.J. Helv. Chim. Acta., 1960, vol. 43, pp. 64-68.

21. Dubois M., Gilles K.A., Hamilton J.K., Rebers P.A., Smith F. Analyt. Chem., 1956, vol. 28, pp. 350-356.

Received Juny 30, 2015

Revised March 4, 2016

\footnotetext{
* Corresponding author.
} 